\title{
GMR
}

\section{Genomic characterization and phylogenetic analysis of Chinese sacbrood virus isolated from Loess Plateau, China}

\author{
H. Yu ${ }^{1,2}$, T.X. Liu ${ }^{2}$ and D. Wang ${ }^{1}$ \\ ${ }^{1}$ State Key Laboratory of Crop Stress Biology for Arid Areas Northwest A\&F \\ University, Yangling, Shaanxi, China \\ ${ }^{2}$ Key Laboratory of Applied Entomology, Northwest A\&F University, \\ Yangling, Shaanxi, China \\ Corresponding author: D. Wang \\ E-mail: wanghande@yahoo.com / wanghande@nwsuaf.edu.cn \\ Genet. Mol. Res. 15 (3): gmr.15036928 \\ Received March 31, 2016 \\ Accepted May 31, 2016 \\ Published September 23, 2016 \\ DOI http://dx.doi.org/10.4238/gmr.15036928
}

Copyright (C) 2016 The Authors. This is an open-access article distributed under the terms of the Creative Commons Attribution ShareAlike (CC BY-SA) 4.0 License.

\begin{abstract}
The complete genomic RNA of the Chinese sacbrood virus (CSBV) strain, which infects the honeybees in the Loess plateau, was sequenced and analyzed. The CSBV-SX strain contains 8705 nucleotides, which includes a single large open reading frame (99-8681 nucleotides) encoding 2860 amino acids. A novel efficient identification method was used to investigate the samples infected by CSBV. The putative amino acid sequence alignment analysis showed that, except for some normal well characterized domains such as RNA helicase, RNA protease, and RNA-dependent RNA polymerase domains, a calicivirus coat protein domain was identified at amino acids 493-564. Phylogenetic analysis indicated that CSBVSX was closely related to CSBV-BJ, and this result was supported by nucleotide multiple sequence alignment and protein multiple
\end{abstract}

Genetics and Molecular Research 15 (3): gmr.15036928 
sequence alignment analysis results. These differences in the CSBVSX strain may be related to virus adaptation to the xerothermic, low relative humidity, and strong ultraviolet radiation conditions in the Loess Plateau.

Key words: Apis cerana; Chinese sacbrood virus; Genome sequence; Honeybee

\section{INTRODUCTION}

Honeybees (Apis cerana cerana Fabricius) are important pollinators of agricultural and landscape plants cultivated worldwide, and are irreplaceable for their contribution to our lives (Winston, 1987; Martin, 2001). However, the health and vitality of honeybees is threatened by various pathogenic microorganisms, including fungi, bacteria, nematodes, parasitic mites, protozoa, and viruses (Bailey and Ball, 1991; Ellis and Munn, 2005). Among these disease agents, viruses can lead to a major economic consideration disease in apiculture.

Sacbrood virus (SBV) is one of the most common and widespread of the 19 viruses known to infect honeybees (Chen and Siede, 2007; Neumann and Carreck, 2010; VanEngelsdorp et al., 2010). SBV infects both larvae and adult bees, and there are no disease symptoms in SBV-infected adult bees (Berényi et al., 2007). The color of the SBV infected larvae change from pearly white to pale yellow, and fail to pupate, with ecdysial fluid accumulating beneath their unshed skin, forming a sac (Bailey, 1975). Sacbrood virus was first described in 1913, but it was not characterized until 1964 (Bailey et al., 1964). $\mathrm{SBV}$ is generally referred to as picornavirus for its biophysical properties and the presence of an RNA genome, but it has been reclassified into the genus Iflavirus, which contains linear positive single-stranded RNA viruses (Moore et al., 1985; Mayo, 2002; Baker and Schroeder, 2008). This RNA genome is monopartite monocistronic, with structural genes arranged at the $5^{\prime}$ end and non-structural genes at the $3^{\prime}$ end. The SBV particles are $28 \mathrm{~nm}$ in diameter and are non-enveloped, round, and featureless in appearance (Brcak and Kralik, 1965; Bailey, 1968).

The complete genomic sequence of SBV-UK was first determined by Ghosh et al. (1999). The Chinese SBV (CSBV) sequence was first determined in 2001, and 4 CSBV sequences have been reported, including CSBV-GZ, CSBV-LN, CSBV-BJ, and CSBV-FZ. CSBV is similar to SBV-UK in its physiological and biochemical features, but differs in antigenicity and do not show cross-infection. Sequence analysis indicated that CSBV has some differences, but is highly homologous to SBV-UK (Zhang et al., 2001). The CSBV genome is composed of a positive single-stranded RNA, which encodes for 4 structural proteins.

China includes a large amount of land, crossing nearly $63^{\circ}$ in longitude and $50^{\circ}$ in latitude; diverse landforms can be found in this range. There are large differences between the north and south in terms of climate as well as different landforms in China. These geographic variances or climate changes lead to differences between the different CSBV isolates reported in China. The CSBV reported in this study was isolated from the Loess Plateau, which has xerothermic climate, low relative humidity, and strong ultraviolet radiation. Therefore, studies of CSBV-SX provide information regarding the genetic background of SBV.

Genetics and Molecular Research 15 (3): gmr.15036928 


\section{MATERIAL AND METHODS}

\section{Sample collection}

Infected honeybees (A. cerana) used in this study originated from Yulin in northwest Shaanxi Province, China. The larvae were collected from sacbrood outbreaks in May 2012 and stored frozen at $-80^{\circ} \mathrm{C}$ until use. The CSBV-SX sequence described in this study was submitted to GenBank under accession No. KJ000692.

\section{Identification of CSBV with gradient band polymerase chain reaction (PCR)}

Viral RNA was extracted from infected honeybees using RNAiso plus (TaKaRa, Shiga, Japan) according to the manufacturer instructions and digested with RNase-free DNase set (TakaRa). Synthesis of first-strand DNA complementary to the total RNA was carried out using a RevertAid First Strand cDNA Synthesis Kit (Thermo Scientific, Waltham, MA, USA) with oligo(dT) primers and random primers according to the manufacturer instructions.

All samples were first tested by nested-PCR with 4 pairs of outer primers and followed by 4 pairs of inner primers to confirm CSBV infection (Table 1). Another 5 pairs of primers (Table 1) located at 5 different regions of the CSBV genome were designed to produce increasing sizes of PCR products from 250 to $1500 \mathrm{bp}$. These primers would result in a gradient band version for fast identification of CSBV. rTaq DNA polymerase (TaKaRa) was used to amplify the products according to the manuscript in a S1000 Thermal Cycler (BioRad, Hercules, CA, USA). All products were sequenced and blasted to verify the accuracy of identification.

\section{PCR amplification of viral RNA}

To amplify the internal region of the CSBV-SX genome, 8 primer pairs (Table 1) were designed based on the sequences of CSBV-GZ and SBV-UK. cDNAs were synthesized as described above. Next, $1 \mu \mathrm{L}$ each cDNA was PCR-amplified using HS Taq (TaKaRa) according to instructions. The amplified products were purified using a TIANgel Midi Purification Kit (Tiangen, Beijing, China) and ligated into the pGEM-T easy vector (Promega, Madison, WI, USA) by T-A ligation. For each part, 5 clones were selected for sequencing.

The 5'RACE and 3'RACE procedure was performed using the 5'-Full RACE Kit and 3'-Full RACE Core Set Kit (TaKaRa) with $1 \mathrm{mg}$ purified total RNA isolated from SBVinfected honeybee larvae. The amplified products were purified and ligated into the pGEM-T easy vector. Ten clones were selected for sequencing.

\section{Nucleotide sequencing and analysis}

The nucleotide sequence of each fragment was assembled to build a continuous complete sequence using the SeqMan program. Multiple nucleotide and deduced amino acid sequence alignments were performed using published SBV sequences. A phylogenetic tree was constructed using the MEGA 5.05 package and the neighbor-joining method (Saitou and Nei, 1987) with Kimura's 2-parameter model (Kimura, 1980), and bootstrap values were based on 500 replicates.

Genetics and Molecular Research 15 (3): gmr.15036928 
Table 1. Primers used to identify the virus and obtain the complete nucleotide sequence of CSBV-SX.

\begin{tabular}{|c|c|c|c|}
\hline Primer & Sequence (5'-3') & Location & PCR products (bp) \\
\hline \multicolumn{4}{|c|}{ Nested PCR primers } \\
\hline CSBV1O-F & CAAGGTGGCTTCAGAAATAGCT & $520-541$ & 351 \\
\hline CSBV1O-R & GCGTGAGTTGACAGAAAATC & $852-871$ & \\
\hline CSBV1I-F & AGTATATTGGTGCAATTTGT & $549-568$ & 297 \\
\hline CSBV1I-R & GATGTAATATTGTGCTAAAA & $826-845$ & \\
\hline CSBV2O-F & CCTAGTGTGAATCCGAGTA & $2871-2889$ & 430 \\
\hline CSBV2O-R & TTGCACGCTCAGGAGTTACT & $3281-3300$ & \\
\hline CSBV2I-F & GTACCATTTGATACTGAAAA & $2901-2920$ & 369 \\
\hline CSBV2I-R & CATATTACACAACGTACTAA & $3250-3269$ & \\
\hline CSBV3O-F & GATTGTTACTTTTCTGA & $5961-5977$ & 410 \\
\hline CSBV3O-R & AATGTTCTAGTTGTTCGCCT & $6351-6370$ & \\
\hline CSBV3I-F & AACGGTATAAGGAGGAAAA & $6004-6023$ & 321 \\
\hline CSBV3I-R & TAGGAACGAACTCAACACGC & $6305-6324$ & \\
\hline CSBV4O-F & GCCCATTACCGTGGTGATA & $8141-8159$ & 400 \\
\hline CSBV4O-R & TAAATCAGCACATTCCCATA & $8481-8500$ & \\
\hline CSBV4I-F & AGTAAAGAAAGAGGGCAAAC & $8214-8233$ & 253 \\
\hline CSBV4I-R & GTGGATACACTTCGTGGG & $8449-8466$ & \\
\hline \multicolumn{4}{|c|}{ Gradient bands PCR primers } \\
\hline CSBV250-F & AGTAAAGAAAGAGGGCAAAC & $8068-8087$ & 250 \\
\hline CSBV250-R & GTGGATACACTTCGTGGG & $8300-8317$ & \\
\hline CSBV500-F & GCGTGTTGAGTTCGTTCCTAGTGG & $7520-7543$ & 500 \\
\hline CSBV500-R & TTGGGGCCAACAATAAGGACCCT & $7997-8019$ & \\
\hline CSBV750-F & GTACGGAGAGGCCCCACTTT & $1025-1044$ & 750 \\
\hline CSBV750-R & CTTCTAAACTGGGTCCTTCCCAA & $1752-1774$ & \\
\hline CSBV1000-F & CCAGGTGTATTACTATCCGCC & $4120-4140$ & 1000 \\
\hline CSBV1000-R & TCTAGATAAGATTGGAGAGGCAC & $5097-5119$ & \\
\hline CSBV1500-F & CCCAACGGTATAAGGAGGAA & $6000-6019$ & 1500 \\
\hline CSBV1500-R & AATACTGTATATCAGGAAAGCCA & $7478-7500$ & \\
\hline \multicolumn{4}{|c|}{ RACE analysis primers } \\
\hline 5RACEouter & TTCCTTAGAACTTTGCTGTGTAGCG & $626-650$ & \\
\hline 5RACEUinner & TTCCTTCTGCGGTCTTAATTGACACTGCACGTCTAA & $448-483$ & \\
\hline 3RACEDouter & TGTACCAACAGAAGTGTGGGTC & $8107-8128$ & \\
\hline 3RACEDinner & AGAATTGTTCTGCTACGGTGATGATTTGATAATGTC & $8258-8293$ & \\
\hline \multicolumn{4}{|c|}{ Genome partial sequence primers } \\
\hline CSBVP1-F & TCGAGATTTACCTTGACGG & 119 & 1500 \\
\hline CSBVP1-R & CACTCTTACCTTTCCCATG & $1482-1500$ & \\
\hline CSBVP2-F & TTATCAAGCTGATAATATAA & $1001-1020$ & 1500 \\
\hline CSBVP2-R & GATACTTGGGTGTCCAAAGA & $2481-2500$ & \\
\hline CSBVP3-F & AAGGCAGATAATGTTAGTAA & $2001-2020$ & 1500 \\
\hline CSBVP3-R & AGCCTCCTTAACCGCTGTA & $3482-3500$ & \\
\hline CSBVP4-F & TGGTTGTAACACCTGTA & $3001-3017$ & 1500 \\
\hline CSBVP4-R & GCTGGTATAATTCCGAAA & $4483-4500$ & \\
\hline CSBVP5-F & AACATCGGCTACGATACA & $4001-4081$ & 1500 \\
\hline CSBVP5-R & CCCATAATTAATGCACGCC & $5482-5500$ & \\
\hline CSBVP6-F & GATGTTACGACTGGGTT & $5001-5017$ & 1500 \\
\hline CSBVP6-R & CACACGGCCCGCGGGTTTAT & $6481-6500$ & \\
\hline CSBVP7-F & CCCAACGGTATAAGGAGGA & 6001-6019 & 1500 \\
\hline CSBVP7-R & AATACTGTATATCAGGA & $7484-7500$ & \\
\hline CSBVP8-F & GGGTCGAGGTGAGGGAT & $7001-7017$ & 1740 \\
\hline CSBVP8-R & ATATGAGACCTTAAAAAACA & $8721-8740$ & \\
\hline
\end{tabular}

\section{RESULTS}

\section{Gradient band reverse transcription-PCR analysis}

All samples were first tested by nested-PCR with 4 pairs of outer primers, followed by another 4 pairs of inner primers (Table 1). Four clear bands of expected size were observed with the first round of PCR amplification using the outer primers (Figure 1A). In the second 
round of PCR amplification using the 4 pairs of inner primers, another 4 bands of predicted size were observed (data not shown). All PCR products were sequenced and blasted, revealing high identity with CSBV-BJ, indicating that our samples were CSBV-infected and the bands were from the CSBV genome.

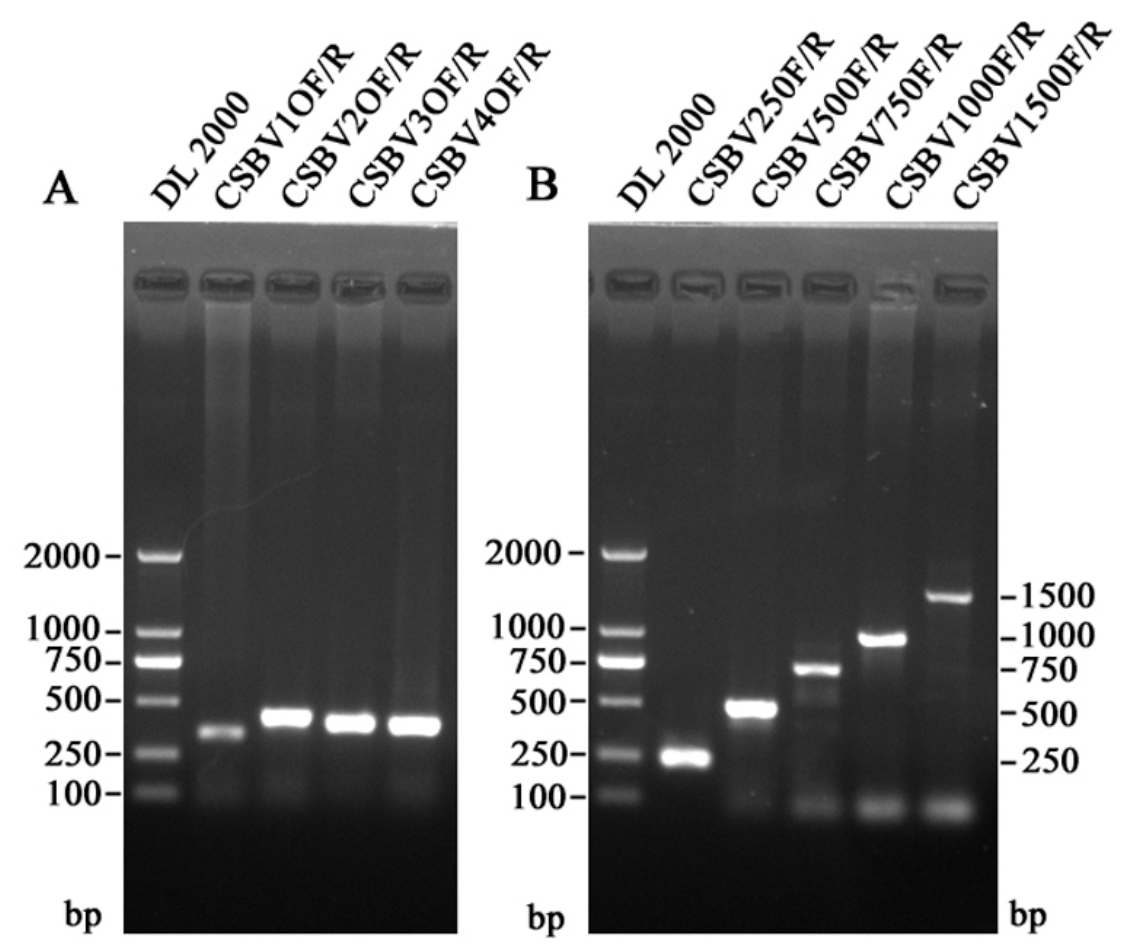

Figure 1. SBV-infected sample identified by reverse transcription-PCR. A. PCR products with outer primers of nested PCR electrophoresed on 1\% agarose gel, stained with ethidium bromide, and visualized under UV light; B. representative PCR products separated by $1 \%$ agarose gel electrophoresis as a stair-step graph by gradient band PCR. Lane: DL 2000, DNA ladder 2000 (TaKaRa).

To investigate the CSBV infection in a more efficient manner, an additional 5 pairs of primers were used to amplify 5 parts located in 5 different regions of the SBV genome were used (Table 1). With the amplification of these gradient band primers, 250-, 500-, 750-, 1000-, and 1500-bp PCR products were presented in each lane as gradient up-steps, which were in similar to the predicted sizes with each pair of primers, respectively (Figure 1B). This gradient band phenomenon is strong evidence for SBV-positive samples. Sequencing was conducted to confirm these results.

\section{Nucleotide sequence analysis}

The complete genome of CSBV-SX was composed of $8705 \mathrm{bp}$, excluding the poly A tail. The base composition of CSBV-SX was A (29.73\%), C (16.32\%), G (24.53\%), and $\mathrm{U}(29.39 \%)$. The CSBV-SX genome contained a single large open reading frame encoding 
2860 amino acids, starting at nucleotide 99 and ending with a stop codon TAG at nucleotide 8681. Multiple sequence comparison showed that CSBV-SX was genetically closely related to CSBV-GZ (93.2\%) and was closest to CSBV-BJ (97.5\%) (Table 2).

Table 2. Homology (\%) analysis between CSBV-SX and other referenced virus strains.

\begin{tabular}{l|c|c|c|c|c|c|c}
\hline & SBV-UK & CSBV-BJ & CSBV-GZ & CSBV-LN & SBV-Kor19 & SBV-Kor21 & SBV-Korean \\
\hline Nucleotide sequence & $88.9 \%$ & $97.5 \%$ & $93.2 \%$ & $90.9 \%$ & $90.5 \%$ & $88.3 \%$ & $90.8 \%$ \\
\hline Putative amino acid sequence & $95.5 \%$ & $98.8 \%$ & $96.3 \%$ & $96.0 \%$ & $95.1 \%$ & $94.6 \%$ & $95.4 \%$ \\
\hline
\end{tabular}

Multiple sequence alignment showed that the $5^{\prime}$ sequence of CSBV-SX was similar to that of the SBV-UK strain. Alignment of the region showing the largest number of differences, from 3160 to 3205 nucleotides, showed that the CSBV-SX strain contained a sequence that was similar to those in the CSBV-BJ, CSBV-GZ, or SBV-Kor21 strains. Compared with SBVKorean or SBV-Kor19, CSBV-SX contained a region that was 34-nucleotides longer. An additional 30-nucleotide addition was observed compared with CSBV-LN, SBV-K5B, and SBV-K1A. In this region showing variability in sequence length, CSBV-SX was 3 nucleotides longer than SBV-UK (Figure 2).

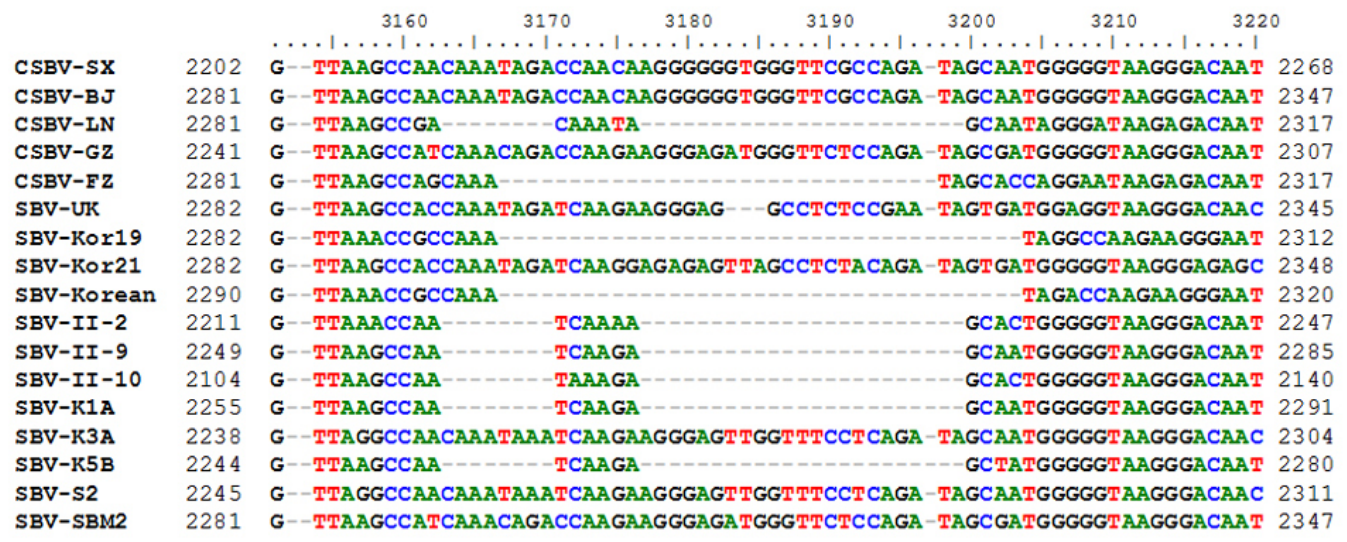

Figure 2. Alignment of nucleotide sequences of the reported SBV strains at the region located between nucleotides 3160 and 3205 , which was the most different region in the genome alignment.

\section{Amino acid sequence analysis}

The BLAST result of the predicted amino acid sequence for CSBV-SX showed that an RNA-dependent RNA polymerase domain (located at amino acids 2504-2795), 3 picornavirus capsid protein domain (located at amino acids 213-388, 494-681, and 791-983), and an RNA helicase motif (located at amino acids 1377-1486) were found in this deduced amino acid sequence. Interestingly, a calicivirus coat protein motif was found at amino acids 439-564, which was the first time this motif has been identified in the SBV encoded protein. These results indicate that structural proteins are located in the $\mathrm{N}$-terminal region, while nonstructural proteins are located in the $\mathrm{C}$-terminal region.

Genetics and Molecular Research 15 (3): gmr.15036928 
The predicted amino acid sequences for CSBV-SX and other strains were then aligned and compared as described above. Multiple sequence comparison showed that the deduced CSBV-SX amino acid sequence was closely related to CSBV-GZ (96.3\%) and most closely related to CSBV-BJ (98.8\%) (Table 2). This result was supported by our nucleotide sequence comparison results. Analysis of the structural protein regions indicated that the length of the amino acid sequence of CSBV-SX was similar to those of CSBV-BJ, CSBV-GZ, and SBVKor21 from 693 to 762 amino acids, which was 1 amino acid longer than that of SBV-UK in this region and 13 amino acids longer than CSBV-LN (Figure 3).

\begin{tabular}{|c|c|c|}
\hline CSBV-SX & 93 & PPDGYDPVKPTNRPTRGVGSPDSNGGKGQSAVAVPDNPHRFLPANVSNRWNEYSSAYLPRVQMDTGDK 762 \\
\hline CSBV-BJ & 693 & YDPVKPTNRPTRGVGSPDSNGGKGQSTVAVSDNPHRFLPANVSNRWNEYSSAYLPRVQMDTGDK 762 \\
\hline CSBV-LN & 693 & SFPPDGYDPVKPTN----------SNRDKRQ---SVVDNPHRFLPANVSNRWNEYSSVYLPRVQMDTGAK 749 \\
\hline CSBV-GZ & 693 & SFPPDGYDPVKPSNRPRREMGSPDSDGGKGQSVVAGSDNPHRFLPANVSNRWNEYSSAYLPRVQMDTGAK 762 \\
\hline CSBV-FZ & 693 & SFPPDGYDPVKPANSTR----------NKRQSVVD---NPHRFLPANVSNRWINYSSAYLPRVQMDTGAK 749 \\
\hline SBV-UK & 693 & SFPPDGYDPVKPPNRSRRE-ASPNSDGGKGQPEVAVSDNPHRELPANVSNRWNEYSSAYLPRVQMDTGAK 761 \\
\hline SBV-Kor19 & 693 & SFPPDGYDPVKPPNRPRRE-----------------SDNPHRFLPANVSNSWNEYSSAYLPRVQMDTGAK 745 \\
\hline SBV-Kor21 & 693 & SFPPDGYDPVKPPNRSRRELASTDSDGGKGEPVSVGSDNPHRFLPANVSNRWNEYSSAYLPRVQMDTGAK 762 \\
\hline SBV-Korean & 693 & SFPPDGYDPVKPPNRPRRE------------------SDNPHRFLPANVSNSWNEYSSAYLPRVQMDTGAK 745 \\
\hline SBV-II-2 & 693 & --STGGKGQSVVAASNNPHRFLPASVSNFWNEYSSDYLPRVQMDTGDK 752 \\
\hline SBV-II-9 & 693 & SFPPDGYDPVKPIK----------SNGGKGQSVVAVSNNPHRFLPVSVSNLWNEYSSAYLPRVQMDTGDK 752 \\
\hline SBV-II-10 & 693 & SFPPDGYDPVKPIK----------STGGKGQSVVAASNNPHRFLPASVSNLWNEYSSDYLPRVOMDTGAK 752 \\
\hline SBV-K1A & 693 & SFPPDGYDPVKPIK----------SNGGKGQSVVAVSNNPHRFLPVSVSNLWNEYSSAYLPRVQMDTGDK 752 \\
\hline SBV-K3A & 693 & SFPPDGYDPVRPTNKSRRELVSSDSNGGKGQPVVAVSDNPHRFLPANVSNRWNEYSSAYLPRVOMDTGAK 762 \\
\hline SBV-K5B & 693 & SFPPDGYDPVKPIK----------SYGGKGQSVVAVSNNPHRFLPVSVSNLWNEYSSAYLPRVQMDTGDK 752 \\
\hline SBV-S2 & 693 & SFPPDGYDPVRPTNKSRRELVSSDSNGGKGPVVAVSDNPHRFLPANVSNRWNEYSSAYLPRVQMDTGAK 762 \\
\hline SBV-SBM2 & 693 & SFPPDGYDPVKPSNRPRREMGSPDSDGGKGSVVAASDNPHRFLPANVSNRWNEYSSAYLPRVQMDTGAK 762 \\
\hline
\end{tabular}

Figure 3. Alignment of the putative amino acid sequences regions between amino acids 693 and 762 of the SBV strains.

Next, we determined the homology of the deduced amino acid sequences for alignment analysis focused on the conserved domains. As a representative of the Iflaviridae family, deformed wing virus and Varroa destructor virus were selected with SBV strains for comparison, and acute bee paralysis virus, Kashmir bee virus, Drosophila $\mathrm{C}$ virus, black queen cell virus, Plautia stali intestine virus, and Phopalosiphum padi virus were used to represent the Dicistorviridae family. In the alignment, conserved RNA-dependent RNA polymerase domains were identified in amino acid sequences between amino acids 2496 and 2674 in the Iflaviridae family and from amino acid position 1300 to 1748 in the Dicistroviridae family (Figure 4). The RNA helicase domains, which contained the highly conserved amino acids GxxGxGKS and Qx5DD (Koonin and Dolja, 1993), were located between amino acids 1348 and 1574 in the Iflaviridae family (Figure 5). These positions were found between amino acids 431 to 690 in the Dicistorviridae family (Figure 5). The GxCG and GxHxxG domains were identified within the protease domain in the deuced amino acid sequences of the viruses. These motifs were found between amino acids 2219 and 2342 in the Iflaviridae family, and from amino acids 1050 to 1430 in the Dicistroviridae family (Figure 6).

\section{Phylogenetic analysis}

Phylogenetic analysis was conducted using complete CSBV-SX genome sequences to determine the probable genetic relationships among the virus strains (Figure 7). The viruses were segregated into 2 groups in the phylogenetic tree according to their taxonomic

Genetics and Molecular Research 15 (3): gmr.15036928 
classifications (Iflavirus and Dicistroviridae). The phylogenetic tree showed that CSBV-SX was classified onto the same branch as the CSBV-BJ strain, and next to the branch containing the CSBV-LN strain, which was slightly farther away from the branch containing the SBV-UK and SBV-Kor21 strains.

I

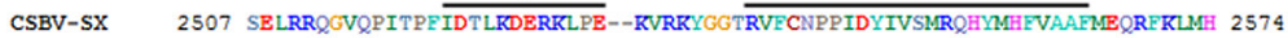
CSBV-BJ 2507 SBLRRQGVQPITPFIDTLKDERKLPB--KVRKYGGTRVECNPPIDYIVSMRQHYMHEVAAFMEQRFKLMH 2574 CSBV-LN 2494 SBLRRQGVQPITPFIDTLKDBRKLPB--KVRKYGGTRVFCNPPIDYIVSMRQYMMFVAAFMBQRFKLMH 2561 CSBV-GZ 2507 SBLRRQGVQPITPFIDTLKDERKLPB--KVRKYGGTRVFCNPPIDYIVSMRQYYMHFVAAFMBQRFKLMH 2574 CSBV-FZ 2494 SBLRRQGVQPITPFIDTFKDERKLPB--KVRKYGGTRVECNPPIDYTVSMRQYMHFVAAFMRQRFKLMH 2561 SBV-UK 2505 SBLRKQGVQPITPFIDTLKDERKLPB--KVRKYGGTRVECNPPIDYIVSMRQYMHPVAAFMEQRFKLMH 2572 SBV-Kor19 2489 SBLRRQGVQPITPFIDTLKDERKLPB--KVRKYGGTRVFCNPPIDYTVSMRQYMMHFVAAFMBQRFRLMH 2556 SBV-Kor21 2506 SBLRKRGVQPITPFIDTLKDBRKLPB--KVRKYGGTRVFCNPPIDYIVSMROYYMHFVAAFMBORFKLMH 2573 SBV-Korean 2489 SBLRRQGVQPITPFIDTLKDBRKLPB--KVRKYGGTRVFCNPPIDYIVSMRQYYMHFVAAFMBQRFRLMH 2556 SBV-II-2 2496 SBLRRQGVQPITPPIDTLKDERKLPB--KVRKYGGTRVFCNPPIDYIVAMRQYYMHFVAAFMBHRFKLMH 2563 SBV-II-9 2496 SBLRRQGVQPITPFIDTLKDERKLPB--KVRRYGGTRVECNPPIDYIVSMRQYFMHFGDAFMEHRFKLMH 2563 SBV-II-10 2496 SBLRRQGVQPITPEIDTLKDERKLPB--KVRKYGGTRVECNPPIDYIVSMRQYFMHEVAAFMEQRFKLMH 2563 SBV-K1A 2496 SBLRRQGVQPITPFIDTLKDBRKLPB--KVRKYGGTRVFCNPPIDYIVSMRQYYMHFVAAFMBHRFKLMH 2563 SBV-K3A 2506 SBLRRQGVQPITPFIDTLKDBRKLPB--KVRKYGGTRVECNPPIDYIVSMRQYYMHFVAAFMGHRFKLMH 2573 SBV-K5B 2496 SBLRRQGVQPITPFIDTLKDERKLPB--KVRRYGGTRVFCNPPIDYIVSMRQYYMHFVAAFMBHRFKLMH 2563 SBV-S2 2506 SELRRQGVQPITPFIDTLKDERKLPB--KVRKYGGTRVECNPPIDYIVSMRQYMHFVAAPMRHRFKLMH 2573 SBV-SBM2 2506 SBLRRQGVQPITPEIDTLKDERKLPB--KVRKYGGTRVECNPPIDYIVSIRQYMMHVAAFMEQRFKLMH 2573 DWV 2543 QLMRKKGIKPHTIPTDCLKDTCLPVB--KCRIPGKTRIFSISPVQFTIPERQYYLDFMASYRAARLNABH 2610 VDV1 2543 QLMRKKGMIRPHTIPTDCLKDTCLPVB--KCRIPGKTRIFSISPVQFTIPFRQYYLDFMASYRAARLNABH 2610 ABPV 1549 IQNARNGVRTPVMVDTLKDERRPIB--KVDQLK-TRVFSNGPMDSITPRMYYLGPIAHLMENRITNBV 1615 KBV 1581 LQAAREGKRLPVMWDTLKDERRPIB--KVNQLK-TRVFSNGPMDFSIAFRMYLGPIAHLMENRITNBV 1647 DCV 1394 IBDCASGKISNVIFVDTLKDERRDIA--KV-NVGKTRVFSAGPQHFVVAFRQYFLPFAAWLMHNRISNBV 1460 BQCV 1300 IBAARQGKILDHYFIDTLKDBRKP-----KHKAHKSRMFSNGPIDYLVWSKMYFNPIVAVLSELKNVDHI 1364 PSIV 1452 BSLAMGISSVHVFIDTLKDERKAIBKA-----HKTRLFSASPLPYLILCRMYLQGGVSRIRGKIVNNI 1516 RhPV 1612 BTDILNGTRPEIVWTDTLKDQRIAIA---KANAGKTRLFSAAPMHYAIALRKVCAPFVAHLSRMRIRNTI 1678 III IV

CSBV-SX 2575 AVGINVQSTEWTLLASKLLAKGNICTIDYSNFGPGFNAOIAKAAME LANRWTMEHVEGVN--------- 2635

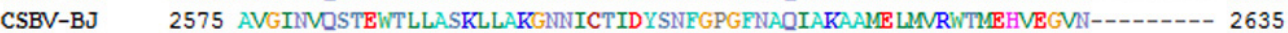

CSBV-LN 2562 AVGINVQSTEWTLLASKLLAKGNNICTIDYSNFGPGFIAOIAKAAMELANRWTMEHVEGVN--------- 2622

CSBV-GZ 2575 AVGINVQSTEWTLLASKLLAKGNNICTIDYSNFGPGFIAOIAKAAME LAMRWTMEHVEGVI---------- 2635

CSBV-FZ 2562 AVGINVOSTEWTLLASKLLAKGNNICTIDYSNFGPGFNAOIAKAAIELINRWTMEHVEGVN--------- 2622

SBV-UK 2573 AVGINVQSTEWTLLASKLLAKGNICTIDYSNFGPGFIAOIAKAAMELAMRWTMEHVEGVN---------- 2633

SBV-Kor19 2557 AVGINVQSTEWTLLASKLLAKGMNICTIDYSNFGPGFNAOIAKAAIE LWRWTIEHVEGVN--------- 2617

SBV-Kor21 2574 AVGINVOSTEWTLLASKLLAKGNICTIDYSNFGPGFNAOIAKAAME LANRWTIVHVEGVN--------- 2634

SBV-Korean 2557 AVGINVQSTEWTLLASKLLAKGNNICTIDYSNFGPGFIAOIAKAAMELINRWTMEHVEGVN--------- 2617

SBV-II-2 2564 AVGINVOSTEWTLLASKLLAKGNNICTIDYSNFGPGFNAOIAKAAMELIVRWTIEHVEGVN--------- 2624

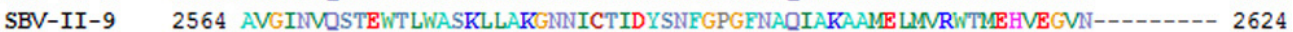

SBV-II-10 2564 AVGINVQSTEWTLLASKLLAKGNNICTIDYSNFGPGFIAOIAKAAIELANRWTMEHVEGVN--------- 2624

SBV-K1A 2564 AVGINVOSTEWTLLASKLLAKGNICTIDYSNFGPGFNAOIAKAAIELMNRWTMEHVEGVN--------- 2624

SBV-K3A 2574 AVGIHVQSTDG-PSGSKLLAKGMNICTIDYSNFGPGFNAOIAKAAMELANRTMEHVEGVN--------- 2633

SBV-K5B 2564 AVGINVQSTEWTLLASKLLAKGNNICTIDYSNFGPGFNAOIAKAAMELIMRWTMEHVEGVN--------- 2624

SBV-S2 2574 AVGINVQSTEWTLLASKLLAKGMICTIDYSFFAPGFNAOIPKAAIELMPRWTIENVEGVN--------- 2634

SBV-SBM2 2574 AVGINVQSTEWTLLTSKLLAKGMNICTIDYSNFGPGFNAOIAKAAME LINRWTMEHVEGVN--------- 2634

DWN

VDV1

ABPV

KBV

DCV

$\mathrm{BOCV}$

PSIV

RhPV

2611 GIGIDVNSLEWTNLATRLSKYGTHIVTGDYKNFGPGLDSDVAASAFEIIIDWVLHYTEEDNKDE------- 2674

2611 GIGIDVISLEWTNLATSLSKYGTHIVTGDYKNFGPGLDSDVAASAFEIIIDWVLNYTEEDDKDE------ 2674

1616 SIGTIVYSQDWNKTVRKLKTMGPKVIAGDFSTFDGSLNVCINIEKFADLANEFYDDGSENAL---------- 1676

1648 SIGTNVYSODWSKTVRKLTKFGNKVIAGDFSTEDGSLNVCINEKEADLANEFYDDGPENAL--------- 1708

1461 AVGTIVYSSDWERIAKRLKTKGSHVIAGDFGNFDGSLVAOILWAIFWEIFWWLKDFIDIENSEG----- 1525

1365 SVGSIVYSTDWDVIARYLKSKSHHIMAGDFEGEDASEOSDILYAAGEVLOELSKKIFNSTED--------- 1426

1517 AVGTNPYSDDWTRVAHHLLRN-RHFVAGDFASYDSSOEKEILRAACEVTVELCED LSLPQSERD------ 1579

1679 CVGVNPFSSEWSAVAOKLLVKGPHVIAGDYSNFDGSLPAOLVYAATEIMADWYD LWWDVVEAHKRIVVG 1748

Figure 4. Alignment of the putative RNA-dependent RNA polymerase domains (RdRp) from all selected virus strains. The motifs identified as RdRp are lined with I-IV.

Genetics and Molecular Research 15 (3): gmr.15036928 


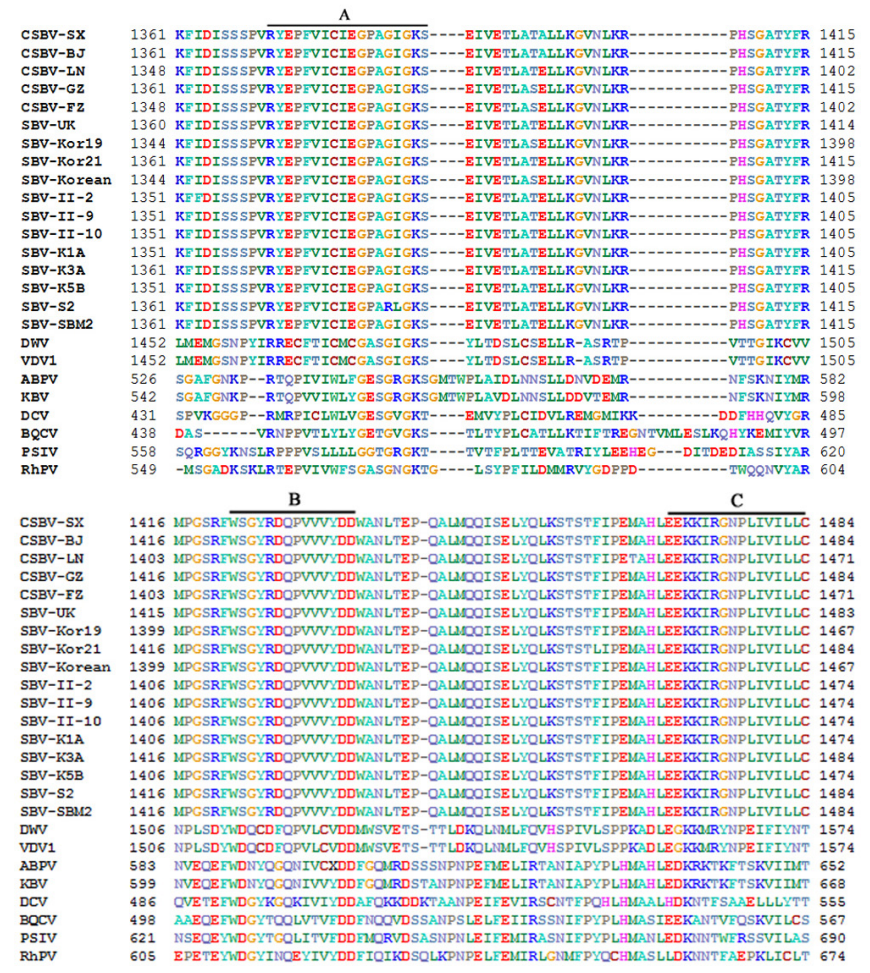

Figure 5. Alignment of the putative RNA helicase domain from all selected virus strains. The motifs identified as RNA helicase domain are lined with A, B, and C.

\section{GXCG GXHXXG}

CSBV-SX 2237 LGLONEMQVSELNGTVFYASDVICYDYSQQGACGSLCFLS-RSQRPIVGMHFAGRGGSCGEGYGVILTK 2305 CSBV-BJ 2237 LGLONENQVSELNGTVFYASDVICYDYSQOGACGSLCFLS-RSORPIVGMHFAGRGEGSCGEGYGVILTK 2305 CSBV-LN 2224 LGLONENOVSE LNGTVFYANDVICYDYSQOGACGS LCFLS-RSORPIVGMHFAGRGEGSCGEGYVILTK 2292 CSBV-GZ 2237 LGLONEWOVSE LNGTVFYANDVICYDYSQQGACGSLCFLS-RSORPIVGMHFAGRGEGSCGEGYGVILTK 2305 CSBV-FZ 2224 LGLONEWOVSE LNGTVFYANDVICYDYSOQGACGSLCFLS-RSORPIVGMHFAGRGEGSCGEGYGVILTK 2292 SBV-UK 2235 LGLQNEMQVSE LNGTVFYANDVICYDYSQQGACGSLCF LS-RSQRPIVGMHFAGRGEGSCGEGYGVILTK 2303 SBV-Kor19 2219 LGLQNEMOVSELNGTVFYANDVICYDYSOQGACGSLCF LS-RSORPIVGMHFAGRGEGSCGEGYGVILTK 2287 SBV-Kor21 2236 LGLQNEMQVSE LNGTVFYANDVICYDYSQQGACGSLCFLS-RSORPIVGMHFAGRGEGSCGEGGVILTK 2304 SBV-Korean 2219 LGLONEMOVSELNGTVFYANDVICYDYSQQGACGSLCFLS-RSQRPIVGMHFAGRGEGSCGEGYGILTK 2287 SBV-II-2 2226 LGLONEWOVSE LNGTVFYANDVICYDYSQQGACGSLCFLS-RSORPIVGMHFAGRGEGSCGEGYGVILTK 2294 SBV-II-9 2226 LGLQNEMOVSE LNGTVFYANDVICYDYSQQGACGS LCFLS-RSQRPIVGMHFAGRGEGSCGEGYGGILTK 2294 SBV-II-10 2226 LGLQNENQVSE LNGTVFYANDVICYDYSQQGACGSLCF LS-RSORPIVGMHFAGRGEGSCGEGYGVILTK 2294 SBV-K1A 2226 LGLONEMOVSE LNGTVFYANDVICYDYSOQGACGSLCF LS-RSORPIVGAHFAGRGERSCGEGYGVILTK 2294 SBV-K3A 2236 LGLONEMOVSE LNGTVFYANDVICYDYSQQGACGS LCF LS-RSORPIVGAHFAGRGEGSCGEGYGVILTK 2304 SBV-K5B 2226 LGLONEMOVSE LNGTVFYANDVICYDYSOQGACGSLCFLT-RSORPIVGMHFAGRGEGSCGEGYGVILTK 2294 SBV-S2 2236 14GLOKEKDGFELNGTVFFSNDVIFFDYSOPGGWGSLCFLF-RSORPIVGMHFAGRGEGSCGEGYGVILNK 2304 SBV-SBM2 2236 LGLONENOVSELNGTVFYANDVICYDYSQOGACGSLCFLS-RSORPIVGMHFAGRGEGSCGEGYVILTK 2304 DWV 2281 ISIN----ADGLYEVILQG--VYTYPYHGDGVCGSILLSR-NLORPIIGIHVAG-TEGLHGFGVAEPLVH 2342 VDV1 2281 ISIN----ADGLYEVILQG--VYTYPYHGDGVCGSILLSR-NLORPIIGIHVAG-TEGLHGFGVAEPLVH 2342 ABPV 1297 TMPTTNGDCGAP---------LVINETQVIRKIAGIHVAG-DARGKAYAESISOKDLIRAFSKIDVSWOI 1356 KBV 1329 TMPTIDGDCGAP---------LIINETQVTRKIAGIHVAG-AACGRAYAESITQKDLERTFSKIDVTMQI 1388 DCV 1144 NAPTRTGDCGSIIG---------LYNKYLERKIIGMHIAGNDAEEHGYACPLTOECLETAFSALVNKNKK 1204 BQCV 1050 SLETISGDCGAP--------LFVTNSKIGPGKIIGIHTAG--GHRFGVGSCFATPFYLEDVKEILSRYDY 1109

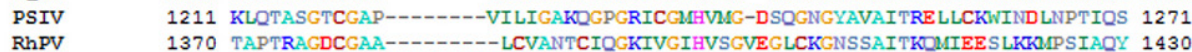

Figure 6. Alignment of the putative RNA protease domain from all selected virus strains. GxCG and GxHxxG motifs were lined in the predicted domain.

Genetics and Molecular Research 15 (3): gmr.15036928 


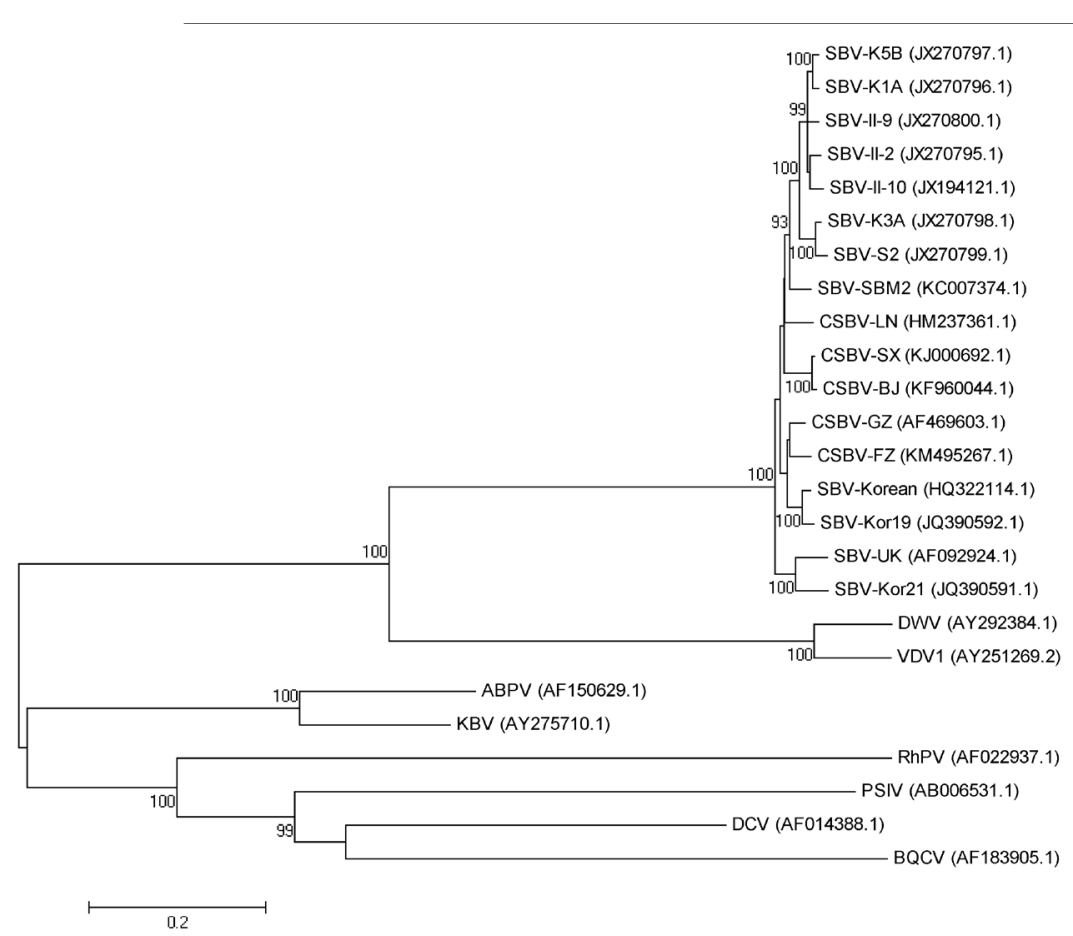

Figure 7. Complete genome sequences of CSBV-SX strain and other complete genome sequences from the GenBank database were used to construct a phylogenetic tree. The GenBank accession Nos. of each virus are shown.

\section{DISCUSSION}

In the present study, a novel gradient band reverse transcription-PCR method was used to identify CSBV infection in $A$. cerana larvae, and the nucleotide sequence of this CSBV was determined. The CSBV-SX genome were monopartite monocistronic and contained a single large open reading frame staring at nucleotide 99 and terminating with a stop codon at nucleotide 8681. Nucleotide alignment analysis and phylogenetic analysis indicated that the CSBV-strain was most closely related to the CSBV-BJ strain. The genomic organization of CSBV-SX was similar to that of the Iflavirus family with structural proteins at the $5^{\prime}$ end and non-structural proteins at the 3 ' end.

Reverse transcription-PCR was successfully used to identify the RNA genomic virus infection, and nested or seminested PCR was used in these identification procedures (Grabensteiner et al., 2001; Choe et al., 2012; Reddy et al., 2013). For nested PCR or seminested PCR, at least 2 rounds of PCR amplification were needed to complete and verify the identification, which were followed by nucleotide sequencing. The gradient band PCR method used in this study was used to identify SBV infection in a rapid manner. The samples infected with SBV exhibited a stair-step graph, with the PCR products separated by agarose gel electrophoresis (Figure 1). Only one round of PCR amplification was required using this novel identification method. This method did not require the PCR products to be sequenced, 
as it is nearly impossible for infection by another virus infection to lead to a similar stair-step graph.

CSBV-SX contained a base composition very similar to that of other SBV strains, including CSBV-BJ, CSBV-GZ, SBV-UK, and SBV-19 (Ghosh et al., 1999; Grabensteiner et al., 2001; Zhang et al., 2001; Chen et al., 2006; Mingxiao et al., 2011; Choe et al., 2012). Genomic alignment analysis showed that CSBV-SX shared high homology with other SBV strains (88.3-97.5\%), and that it was classified into the same group as the CSBV-BJ strain in the complete genomic phylogenetic analysis.

Many well-characterized domains were identified in the CSBV-SX amino acid sequence, such as an RNA helicase domain, RNA protease domain, and RNA-dependent RNA polymerase domain (Koonin and Dolja, 1993; Choe et al., 2012). However, a newly calicivirus coat protein domain located at amino acids 493-564 was identified during BLAST analysis. Whether the protein structure was changed remains unknown. These results indicate that the putative amino acid sequence of CSBV-SX contains universal properties included in other SBV strains, which also includes some unique properties.

In summary, a new strain of SBV was identified and characterized in this study. Additionally, using the gradient band PCR method established in this study, we found that this method is efficient, and it can be applied to identify various types of RNA virus infection. The CSBV-SX strain showed high homology with other SBV strains, including a calicivirus coat protein domain-encoding sequence, which was first reported in the SBV genome. This may be because the virus adapted to the unique climate in the Loess plateau, which is xerothermic, has low relative humidity, and has strong ultraviolet radiation.

\section{Conflicts of interest}

The authors declare no conflict of interest.

\section{ACKNOWLEDGMENTS}

Research supported by the National Natural Science Foundation of China (\#31270691, \#31170609) and a visiting grant from the State Key Laboratory of Virology (Wuhan Institute of Virology, CAS). The authors thank senior livestock engineer Xinyu Liu, Bee Feeding Yards of Yulin city, Shaanxi, China, for generously providing all samples used in this study.

\section{REFERENCES}

Bailey L (1968). Honey bee pathology. Annu. Rev. Entomol. 13: 191-212. http://dx.doi.org/10.1146/annurev. en.13.010168.001203

Bailey L (1975). Recent research on honey bee viruses. Bee World 56: 55-64. http://dx.doi.org/10.1080/000577 2X.1975.11097544

Bailey L and Ball BV (1991). Honey Bee Pathology, 2nd ed. Academic Press, London, UK.

Bailey L, Gibbs AJ and Woods RD (1964). Sacbrood virus of the larval honey bee (Apis mellifera Linnaeus). Virology 23: 425-429. http://dx.doi.org/10.1016/0042-6822(64)90266-1

Baker AC and Schroeder DC (2008). The use of RNA-dependent RNA polymerase for the taxonomic assignment of Picorna-like viruses (order Picornavirales) infecting Apis mellifera L. populations. Virol. J. 5: 10. http://dx.doi. org/10.1186/1743-422X-5-10

Berényi O, Bakonyi T, Derakhshifar I, Köglberger H, et al. (2007). Phylogenetic analysis of deformed wing virus genotypes from diverse geographic origins indicates recent global distribution of the virus. Appl. Environ. Microbiol.

Genetics and Molecular Research 15 (3): gmr.15036928 
73: 3605-3611. http://dx.doi.org/10.1128/AEM.00696-07

Brcak J and Kralik O (1965). On the structure of the virus causing sacbrood of the honey bee. J. Invertebr. Pathol. 20; 110-111. http://dx.doi.org/10.1016/0022-2011(65)90166-7

Chen Y, Evans J and Feldlaufer M (2006). Horizontal and vertical transmission of viruses in the honey bee, Apis mellifera. J. Invertebr. Pathol. 92: 152-159. http://dx.doi.org/10.1016/j.jip.2006.03.010

Chen YP and Siede R (2007). Honey bee viruses. Adv. Virus Res. 70: 33-80. http://dx.doi.org/10.1016/S0065$\underline{3527(07) 70002-7}$

Choe SE, Nguyen LT, Noh JH, Kweon CH, et al. (2012). Analysis of the complete genome sequence of two Korean sacbrood viruses in the Honey bee, Apis mellifera. Virology 432: 155-161. http://dx.doi.org/10.1016/j.virol.2012.06.008

Ellis JD and Munn PA (2005). The worldwide health status of honey bees. Bee World 86: 88-101. http://dx.doi.org/10.10 $\underline{80 / 0005772 X .2005 .11417323}$

Ghosh RC, Ball BV, Willcocks MM and Carter MJ (1999). The nucleotide sequence of sacbrood virus of the honey bee: an insect picorna-like virus. J. Gen. Virol. 80: 1541-1549. http://dx.doi.org/10.1099/0022-1317-80-6-1541

Grabensteiner E, Ritter W, Carter MJ, Davison S, et al. (2001). Sacbrood virus of the honeybee (Apis mellifera): rapid identification and phylogenetic analysis using reverse transcription-PCR. Clin. Diagn. Lab. Immunol. 8: 93-104.

Kimura M (1980). A simple method for estimating evolutionary rates of base substitutions through comparative studies of nucleotide sequences. J. Mol. Evol. 16: 111-120. http://dx.doi.org/10.1007/BF01731581

Koonin EV and Dolja VV (1993). Evolution and taxonomy of positive-strand RNA viruses: implications of comparative analysis of amino acid sequences. Crit. Rev. Biochem. Mol. Biol. 28: 375-430. http://dx.doi. org $110.3109 / 10409239309078440$

Mingxiao M, Ming L, Jian C, Song Y, et al. (2011). Molecular and biological characterization of Chinese sacbrood virus LN isolate. Comp. Funct. Genomics 2011: 409386. http://dx.doi.org/10.1155/2011/409386

Martin SJ (2001). The role of Varroa and viral pathogens in the collapse of honeybee colonies: a modeling approach. $J$. Appl. Ecol. 38: 1082-1093. http://dx.doi.org/10.1046/j.1365-2664.2001.00662.x

Mayo MA (2002). Virus taxonomy - Houston 2002. Arch. Virol. 147: 1071-1076.

Moore NF, Reavy B and King LA (1985). General characteristics, gene organization and expression of small RNA viruses of insects. J. Gen. Virol. 66: 647-659. http://dx.doi.org/10.1099/0022-1317-66-4-647

Neumann P and Carreck NL (2010). Honeybee colony losses. J. Apic. Res. 49: 1-6. http://dx.doi.org/10.3896/ IBRA.1.49.1.01

Reddy KE, Noh JH, Yoo MS, Kim YH, et al. (2013). Molecular characterization and phylogenetic analysis of deformed wing viruses isolated from South Korea. Vet. Microbiol. 167: 272-279. http://dx.doi.org/10.1016/j.vetmic.2013.08.018

Saitou N and Nei M (1987). The neighbor-joining method: a new method for reconstructing phylogenetic trees. Mol. Biol. Evol. 4: 406-425.

VanEngelsdorp D, Speybroeck N, Evans JD, Nguyen BK, et al. (2010). Weighing risk factors associated with bee colony collapse disorder by classification and regression tree analysis. J. Econ. Entomol. 103: 1517-1523. http://dx.doi. org/10.1603/EC09429

Winston ML (1987). The Biology of the Honey Bee. Harvard University Press, Cambridge, UK.

Zhang J, Feng J, Liang Y, Chen D, et al. (2001). Three-dimensional structure of the Chinese Sacbrood bee virus. Sci. China C Life Sci. 44: 443-448. http://dx.doi.org/10.1007/BF02879612

Genetics and Molecular Research 15 (3): gmr.15036928 